\title{
Making Graphic Management Models Smarter
}

Harald Bergsteiner, Macquarie Graduate School of Management, Sydney, Australia

Gayle C. Avery (E-mail: gayle.avery@gsm.mq.edu.au), Macquarie Graduate School of Management, Sydney, Australia

\begin{abstract}
In management, graphic models are an undervalued and poorly used form of theory-building and communication that should be treated with the same rigor that is commonly demanded of text. Graphic models are highly effective for depicting and explaining organizational complexity when designed appropriately. Using two mutual influence models in accountability as an example, we point out common flaws in modelling, and suggest guidelines on how to make graphic models smarter.
\end{abstract}

\section{Introduction}

Graphic models are vastly underused in management, even though in some industries, such as the building industry, graphic language is a primary means of communication and is subject to strict conventions. Thus architects, surveyors, builders and tradesmen learn graphic conventions for cross-sections of timber, concrete, bricks, metal and so on, and use conventions for showing plans, sections, elevations and perspectives (Walker \& Chaplin 1997). However, in most other industries, graphics are rarely employed, eschew strict conventions, and those that are used are frequently flawed. The purpose of this paper is to highlight common problems in designing and using management graphics, using two popular models from the literature as examples.

Exposing organizational complexity using graphics and models is relatively recent (Nadler, Gerstein, Shaw \& Associates 1992; Keidel 1995; Markham 1998; Mintzberg \& van der Heyden 1999), apart from the ubiquitous hierarchical organigrams found throughout industry that tend to show reporting lines and power relationships (Mintzberg \& Van der Heyden 1999). Except for these organigrams, graphical models have generally not been widely adopted for describing and explaining complex organizational issues. This is despite growing recognition of the contribution that graphic models can make to clarifying concepts and thinking in organizational and other complex studies (Markham 1998; Branch 1999).

Similar to their low adoption in management practice, graphics do not feature widely in business school courses either. Surveys of top-ranked US universities suggest that communication courses for business students focus almost entirely on written and/or oral communication, both at the undergraduate and graduate levels (Knight 1999a, 1999b; Murranka \& Lynch 1999). In the wider business community, a similar trend is evident. Members of the US Association for Business Communication rated the importance of 30 business communication concepts, finding that the most important concepts all related to written communication, and that graphic communication played an insignificant role (Wardrope \& Bayless 1999).

Media publications also reveal a lack of graphical sophistication (Tufte 1983). In an analysis of graphics in 15 publications from the period 1974-1980, excluding time-series or maps, Tufte found that seven of these publications (marked with an asterisk below) had no statistical graphics based on more than one variable. In descending order of sophistication: Akahata, Asahi Shimbun, Der Spiegel, The Economist, Nihon Keizai Shimbun, Le Monde, Business Week, New York Times, Pravda*, Frankfurter Allgemeine*, The Times*, Washington Post*, Time*, Die Zeit* and Wall Street Journal*. Scientists appear to be more visually literate than non-scientists, since Tufte found that $42 \%$ of a sample of 220 graphics in Science 1978-1980 used more than one variable. 
It is clear that graphics depicting complexity are overall rare in industry, management education, and the financial media. The Cinderella existence of graphic communication in the management field is unfortunate given: (a) the power of graphics; (b) that visual literacy, like reading and writing, is not innate, but needs to be taught (Ware 2000); and (c) that visual literacy is easier to teach than reading and writing (Walker \& Chaplin 1997). That graphs and graphics can communicate patterns and relationships that might not otherwise be evident, and can display greater complexity than humans can easily understand, has been argued by many authors (Fry 1981; Vessey 1991; Ware 2000; Wainer \& Velleman 2001). This finding can be readily demonstrated with three questions that can be answered by referring either to a written statement or to a graphic (see text box and Figure 1 below).

Note that what is being described in the upper box in Figure 1, could not be described as conceptually complex, and yet it is almost impossible to answer the questions without resorting to some form of graphic so that one can "picture" the web of relationships better.

\section{Figure 1: The Power Of Graphics}

Given that:

Jane and Kevin report to David; Laura, Michael and Norbert report to Else; Otto and Paul report to Fiona; Quenton and Ross report to George; Susan, Tony and Ulrich report to Henry; Vera and Wolfgang report to Ian; David, Else and Fiona report to Binh; George, Henry and Ian report to Curt; Binh and Curt report to Anthony;

Question 1: How many people report to Binh?

Question 2: Who are all the people that are two levels down from Anthony?

Question 3: How many women occupy leadership positions?

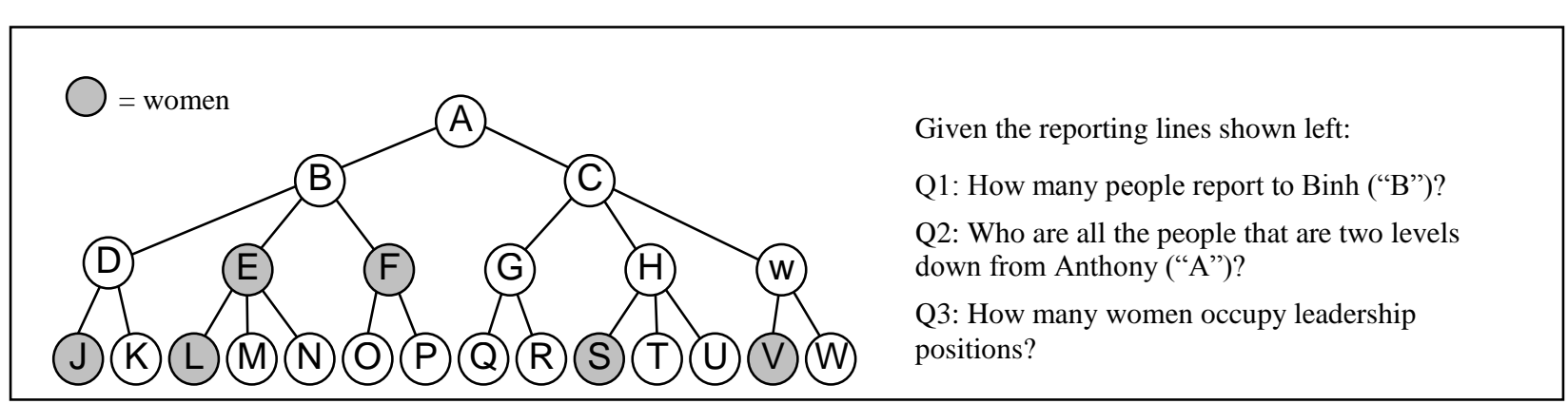

One explanation for this comes from Paivio's work (1978) on dual encoding, which indicated that data are encoded in memory as both images and words. Vessey (1991) uses the terms spatial and symbolic to convey the same meaning. From Fry (1981) and Vessey (1991) the distinctions between graphics/graphs and tables/text in Table 1 can be drawn:

Table 1: Distinction between graphics/graphs versus tables/text Source: Fry (1981); Vessey (1991)

\begin{tabular}{ll}
\hline Graphics and graphs & Text and tables \\
\hline convey continuous information & convey discrete information \\
are spatial, "imagistic", analogic & are symbolic, verbal, analytic \\
emphasize information about relationships & represent discrete data or information \\
preserve explicit information about topology & do not preserve explicit information about topology \\
facilitate viewing of information at a glance & facilitate extracting specific values/arguments \\
elements can be addressed globally & elements need to be addressed separately \\
represent information contemporaneously & represent information sequentially \\
show the 'big picture' or Gestalt & show detail \\
pack a high density of information into small area & high density of information is difficult to achieve \\
\hline
\end{tabular}


However, the utility of graphics goes beyond communicating and explaining. In the natural sciences and technology, the ability to visualize obscure or shrouded processes has led to innovations and insights, particularly in chemistry, molecular modelling, astrophysics and semiconductor design (Van Dam 1992). Thus, it is surprising that the use of graphics is not more widespread in management studies.

\section{Graphic Models In Explaining Complexity}

Glaser \& Strauss (1967), Tufte (1983), Britt (1997) and Gigerenzer \& Selten (2001) have argued that to simplify or ignore complexity does not aid understanding. Scholars of management therefore face the challenge of how to reflect the complexity of that field. In decision theory, "cognitive fit" (Rosch 1978; Klein 1999) occurs when the nature and demands of a problem are reflected in how that problem is represented. Paivio (1978), Vessey (1991) and Wainer \& Velleman (2001) have argued and found that "spatial", "imagistic" and "analogic" graphics provide good "cognitive fit" to the complex communication task outlined above. This strongly suggests that in management theory, particularly in fields such as accountability, the complexity of the problems often demands the use of graphics.

The downside is that graphics also lend themselves to distorting information. For example, Beattie \& Jones' (1992) analysis of graphs in the annual reports of 240 large UK companies for the year 1989, showed a material measurement distortion in 30\% of the graphs. Perhaps this just underscores the relative lack of sophistication of most "consumers" of graphs and models in management.

In summary, graphic models offer a number of advantages over text and they can be highly effective in communicating complexity. However, without visual literacy, it is difficult for communicators - whether academics, auditors, investors or managers - to create, interpret and judge the veracity of complex financial or other organizational graphics (Trumbo 1997). Next, we offer guidelines for using graphical models more effectively.

\section{Model Design}

The first step in designing a model is to consider the elements to be modelled. At their most basic level, management models can generally be seen as tools which provide guidance as to who does what, when, how, for whom, where, in which context, and why (Bergsteiner \& Avery 1999). This $8 \mathrm{~W}$ Model is summarized in Table 2, where a definition of each element and an example is provided. In designing a graphic representation of information or processes, the modeller can then systematically use the $8 \mathrm{~W}$ model to consider all the elements that are to be modelled and apply them to the relevant category.

Table 2: Generic Model: The 8W Model Source: Bergsteiner \& Avery (1999)

\begin{tabular}{|c|c|c|c|}
\hline & & Definition & Examples \\
\hline \multirow{3}{*}{ does } & Who & classes of people & CEO, executive team, leaders, followers \\
\hline & What & classes of actions & research, manufacture, sell, provide services \\
\hline & When & time frames & slots of time, sequences \\
\hline \multirow{3}{*}{ for } & hoW & behaviors etc. & procedures, attitudes, strategies, processes \\
\hline & Whom & classes of people & customers, the public, clients, patients \\
\hline & Where & locations & markets, geographic regions \\
\hline in & Which context & environment & organization, competitors, regulations \\
\hline and & Why & reasons for action & vision, mission, profit, altruism \\
\hline
\end{tabular}

To assist designers of models, Li \& Zhang (1997) and Ware (2000) have proposed another categorization schema that has been expanded on by Bergsteiner \& Avery (1999). Li \& Zhang, and Ware proposed that the components of models essentially fall into three broad categories - Objects (or entities), Relationships and 
Attributes. To this Bergsteiner \& Avery (1999) added a fourth category - Context, creating the ORACle Model. Adopting some of Li \& Zhang's terminology, the alternative schema shown in Table 3 is proposed as a guide for organizing disparate concepts into a coherent pattern. Graphics that incorporate these elements usually take the form of what are generically known as entity-relationship or node-link diagrams (Ware 2000).

Table 3: ORACle Model Elements Applying To Entity-Relationship Or Node-Link Diagrams

\begin{tabular}{|c|c|c|}
\hline Category & Examples & Graphical representation \\
\hline OBJECTS & $\begin{array}{l}\text { - Entities or things (buildings, goods, money, communication } \\
\text { equipment, etc.) } \\
\text { - Actors (individuals, teams, departments, organizations, etc.) }\end{array}$ & $\begin{array}{l}\text { Usually represented by solid graphic } \\
\text { objects (also known as glyphs), which } \\
\text { intuitively makes sense, given that } \\
\text { entities and actors occupy space }\end{array}$ \\
\hline $\begin{array}{l}\text { RELATION- } \\
\text { SHIPS }\end{array}$ & $\begin{array}{l}\text { How the above relate to each other in space, time, importance } \\
\text { or by type, e.g. } \\
\text { - linkages (these can be one-way or two-way and can } \\
\text { represent information flows, actions, activities, operations, } \\
\text { feedback loops, contingencies, etc.) } \\
\text { - sequences (actions in time, choices) } \\
\text { - hierarchies }\end{array}$ & $\begin{array}{l}\text { Usually represented by lines, } \\
\text { with/without arrows; overlaps etc. }\end{array}$ \\
\hline $\begin{array}{l}\text { ATTRIBUTES } \\
\text { OF OBJECTS }\end{array}$ & $\begin{array}{l}\text { - } \quad \text { states (structure, systems, skills, style, etc.) } \\
\text { - } \quad \text { functions (research, promotion, production, sales, etc.) } \\
\text { - } \quad \text { scenarios (visions, strategies, goals, plans, etc.) }\end{array}$ & $\begin{array}{l}\text { Also usually represented by solid graphic } \\
\text { objects because they are "possessed" by } \\
\text { things and actors that occupy space }\end{array}$ \\
\hline CONTEXT & $\begin{array}{l}\text { - location (markets, geographic regions) } \\
\text { - environment (competitors, regulations, etc.) }\end{array}$ & $\begin{array}{l}\text { There is no convention; variously } \\
\text { represented by encircling lines, shading, } \\
\text { text boxes }\end{array}$ \\
\hline
\end{tabular}

The extent to which graphics succeed in effectively communicating complex ideas is a function of several factors. It is our contention that best-practice graphic models and their attendant theory should satisfy the following:

- $\quad$ A requirement for theoretical groundedness and for absolute correspondence between the model and the underlying theory (Glaser \& Strauss 1967; Feigl 1988; Soulliere, Britt \& Maines 2001).

- $\quad$ Take account of complexity and context, instead of oversimplifying (Glaser \& Strauss 1967; Tufte 1983; Freedman 1985; Feigl 1988; Vessey 1991; Britt 1997; Gigerenzer \& Selten 2001; Soulliere, Britt \& Maines 2001).

- $\quad$ Calls for integration (Laughlin 1995; Staats 1999; Piggot 2002).

- $\quad$ The need for a logical and consistent classification/ categorization system. Category theorists hold that well-structured category systems result in a gain in cognitive efficiency (Rosch 1978; Feigl 1988; Britt 1997; Li \& Zhang 1997; Bergsteiner \& Avery 1999; Howard 1999; Klein 1999; Ware 2000).

- An appropriate and consistent graphic syntax for both nodes and links that reflects the above categorization (Britt 1997; Ware 2000).

- $\quad$ The guidelines for good graphic modelling proposed by Fry (1981), Tufte (1983, 1990, 1997), Britt (1997), Walker \& Chaplin (1997), Mintzberg \& Van der Heyden (1999), Tractinsky \& Meyer (1999); Ware (2000). This demands complexity in the content, but parsimony in the means of expression (Tufte 1983); and not omitting important model components, simply because of graphic preconceptions underlying the model. 
- $\quad$ The need for precise definitions of all concepts embodied in graphics and legends that explain the meaning of different categories of nodes and links (Feigl 1988).

- $\quad$ Decision theorists' call for "cognitive fit" between the explanandum and the explanans (Paivio 1978; Rosch 1978; Feigl 1988; Barwise \& Etchemendy 1995; Klein 1999; Wainer \& Velleman 2001). A good match between graphics and the kind of task to be performed results in increased performance with respect to both accuracy and time (Vessey 1991).

- $\quad$ Theorists' demand that models provide logical scientific explanations (Campbell 1920; Hesse 1970; Pylyshyn 1980; Pitt 1981; Nersessian 1995; Hempel 1998).

- Modelling theorists' call for systematic structure, a convincing "architecture" and judicious use of Gestalt theory's principle of continuity and symmetry (Pylyshyn 1980; Feigl 1988; Britt 1997; Ware 2000).

- $\quad$ Britt's (1997) requirement to provide descriptive, interpretive, explanatory and predictive understanding; and his tests for simplification, sufficiency and action.

- $\quad$ The requirement of generalizability (Laughlin 1995; Britt 1997).

In designing models, Tufte (1983, p.51) states that, "graphical excellence is that which gives the viewer the greatest number of ideas in the shortest time with the least ink in the smallest space." In other words, graphics should be free of extraneous clutter. Interestingly, research shows that people tend to use gratuitous graphics when they want to impress and when information being presented is undesirable (Tractinsky \& Meyer 1999). People use more modest presentations when they want to facilitate decision-making and when presented favorable information.

These issues are partly a matter of creating an appropriate conceptual structure for the model, and of achieving an attractive and efficacious graphic design. A detailed discussion of how this can be achieved is beyond the scope of this paper, suffice it to say that not all diagrammatic notations are equally effective. Ware (2000) has proposed a visual grammar, or syntax, for elements of node-link diagrams that authors could consider adopting. Two other key findings of Ware's research that are worthy of adoption are that color coding is good for category information, and that symmetry is a powerful organizing principle.

To what extent is adherence to a consistent graphic syntax desirable? "That's kind off like asking whether, and to what extent and so forth: emphasizing words in sentences should be conformable to a generally recognized giude lines." Few editors of text would accept arbitrary stylistic choices or emphases as contained in the previous sentence. They certainly will not accept incorrect or inconsistent grammar or punctuation. The same rigor should be applied to graphics. However, the management and scientific literatures abound with poorly conceived, arbitrary, and sometimes patently incorrect, graphics.

In the absence of commonly accepted and used guidelines, when authors do use graphic conventions, they should provide an explanatory legend, unless the graphic convention is self-evident. This is accepted practice in cartographic map production, on landscape plans, on engineering drawings, and in many other disciplines. Of 26 models in the accountability literature that one of the authors has recently reviewed, not one has a legend. The more complex graphics become, the more important it is to have a legend (Bergsteiner 2003).

In the next section, we examine two mutual influence models from the accountability literature, identifying their graphical strengths and weaknesses. Given the purpose of this paper to promote a best-practice approach to graphic modelling, we unashamedly adopt what some might consider a nitpicking approach.

\section{Comparing Mutual Influence Models}

The complexity of accountability systems and situations derives largely from people, who by being answerable to others and themselves, are constantly trying to anticipate the reaction of others in order to mutually adapt themselves to one another. This is referred to as mutual influence. Kahn, Wolfe, Quinn, Snoek \& Rosenthal (1964), Katz \& Kahn (1978), Van Sell, Brief \& Schuler (1981), Frink \& Klimoski (1998), and Kleinman \& Palmon 
(2000) have modelled this process with varying degrees of success. This paper compares two models that have been widely cited and influential in the field of accountability. These two models highlight some of the successes and pitfalls in graphical modelling.

In reviewing these models, we have generally been guided by Rosch (1978), Tufte (1983), Vessey (1991), Li \& Zhang (1997), Bergsteiner \& Avery (1999), Klein (1999), Mintzberg \& van der Heyden (1999), Ware (2000), and Gigerenzer \& Selten (2001). More specifically, Trumbo (1997) has suggested a three-step critique process of description, interpretation and evaluation of visual communication. Hence for each model, we will describe the model's intent, and discuss strong and weak points of the model in relation to the apparent intent and accompanying text description. In some cases we will make suggestions, in either text or graphic form, on how a model's flaws might be addressed.

\subsection{Katz \& Kahn's (1978) Organizational Roles Model}

Katz \& Kahn's (1978) role-taking model (Figure 1) is firmly embedded in role theory, which proposed a subset of concepts including the organization as a system of roles, role set, role behavior, role sending, role receiving, role taking, role episode and role expectations. Essentially this model depicts the interaction of "Role Senders" and a "Focal Person", whereby the role sent by the former is associated with certain "Role expectations", and the role received by the Focal Person is associated with certain "behavior". The interactive process, in turn, is influenced by the attributes of the person, and by interpersonal and organizational factors. Although Katz \& Kahn use quite different language from later writers, they clearly envisage accountability. "But let a person stop performing within the range of such acceptability [acceptability as laid down by an accountor], and there will immediately become visible the membership of the role set [those affected by the accountee's behavior], the expectations which they hold, and the means of enforcement at their disposal" (Katz \& Kahn 1978, p.192, our insertions). Note that Katz \& Kahn use the term Role Sender for accountor and Focal Person (or role receiver) for the accountee in an accountability relationship.

Figure 1: Katz \& Kahn (1978) Role Episode Model

Source: Katz \& Kahn (1978)

(Legend and dotted circles added by authors of this paper)
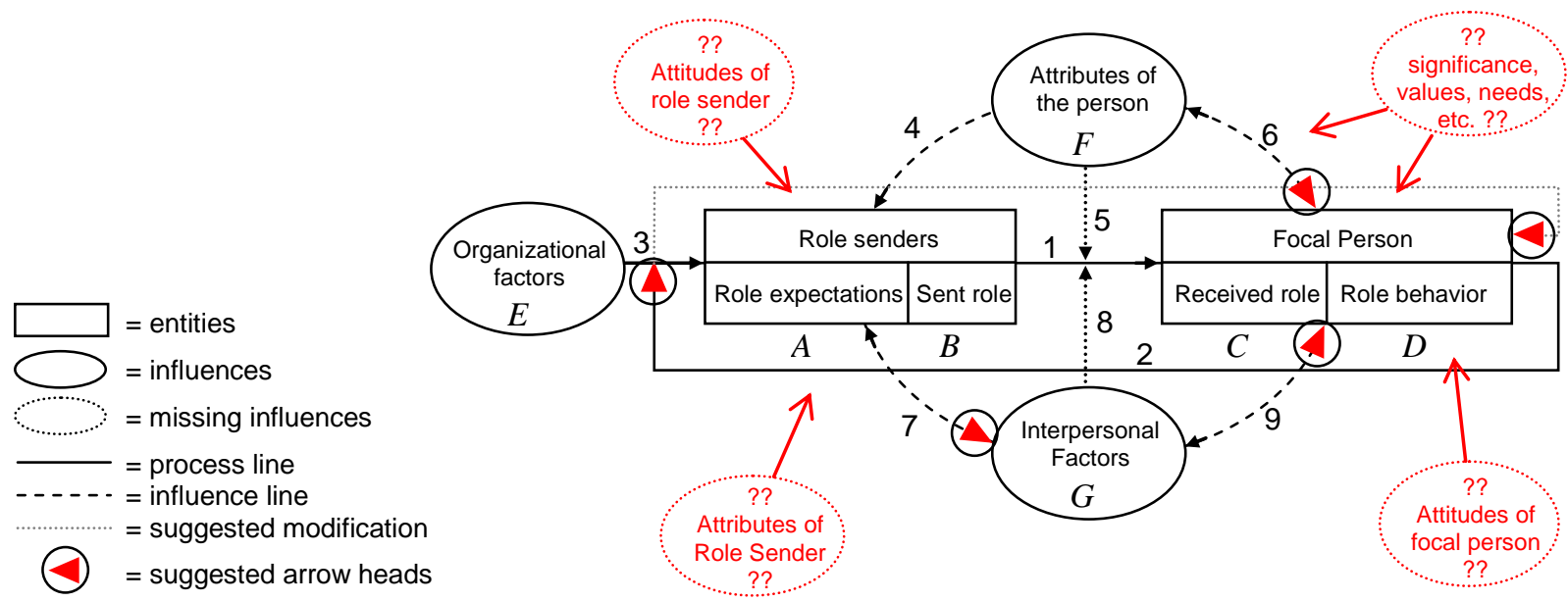

A detailed examination of the Katz \& Kahn graphic, and bearing in mind what Katz \& Kahn said in the accompanying text, reveals some problems with their otherwise deservedly popular model. [The nature of the problem is stated in square brackets at the end of each paragraph]. 
- $\quad$ The model's authors, in their text, refer to personal traits or attributes of both Role Sender and Focal Person (p.211), however, only the Focal Person's attributes are shown on the model. [entity omitted from model]

- $\quad$ In addition to the attributes of both Role Sender and Focal Person, a number of other factors mentioned in the text should be included on the model for both. These include respective significance, personal and work values, needs, attitude to work, work experience, general cognitive ability, conscientiousness, Type A personality, generalized efficacy, trait stress, self-monitoring, agreeableness and locus of control. The problem therefore is not Katz \& Kahn's theory, but that the model oversimplifies a very complex situation. [entities omitted from model]

- $\quad$ Another important dimension, attitudes, is missing completely from the model. Attitudes influence how people behave towards others, whereas expectations have to do with expectations of how others will behave towards us (Avery \& Baker 1990). Both attitudes and expectations can change as accountees and accountors become familiar with each other. For example, if we become more trusting towards someone (an attitude), our expectations as regards their likely behavior will change. "Praise and blame have one set of meanings when they come from a trusted source, another when they stem from untrusted sources" (Katz \& Kahn 1978, p.197). [omission]

- The "Interpersonal Factors" are shown as impacting on the Role Senders only. To the extent that an interpersonal relationship exists, one would expect it to also have an impact on the Focal Person. Katz \& Kahn (1978, p.216) confirm this in their text: "members of school boards (as focal persons) met the expectations of the school superintendent (as role-sender) more fully when they felt liking, admiration, and respect for the person". Arrows 7 and 9 should therefore be bi-directional. [flawed linkage]

- The model shows "Interpersonal Factors" impacting directly on the Role Sender's expectations, and not via the Role Sender's attributes. The following example suggests that attributes are a mediating factor between interpersonal factors and role expectations. A CEO and her personal assistant may both exhibit a certain attribute (e.g. trustworthiness). This fact is likely to influence their interpersonal relationship, which, in turn, is likely to have an impact on the expectations that both hold with respect to each other. [missing linkage]

- The direction of line 2 is ambiguous. Arrow 3 could bifurcate between "E" and "A" to indicate that organizational factors impact on the Role Senders as well as on the Focal Person. Or, line 2 of the model represents a feedback loop from the Focal Person to the Role Senders. Not only is this the meaning that is intended, but, according to Katz \& Kahn, it is one of two core processes. [graphic ambiguity]

- $\quad$ The model suggests, contrary to Katz \& Kahn's text, that organizational factors impact only indirectly on the Focal Person, via the Role Senders. Organizational factors such as structure, size, systems, processes, procedures and culture also have a direct impact on accountees. There should therefore be an arrow from "E" to "C/D". [missing linkage]

- The link "Attributes of the Person" and "Focal Person" (arrow 6) is shown the wrong way round. Arguably, "personality factors" such as traits, values, motives, habits, sensitivities, fears etc., which are relatively stable, influence the way in which an accountee will respond to accountor behavior. In Britt's (1997) language, "the tail of the arrow is placed next to the concept that is thought of as being independent (the thing doing the influencing) ... influence flows along the arrow from tail to head". [flawed linkage]

- Implicit in Katz \& Kahn's model is also the assumption that mutual influencing only occurs directly. However, people often use the services of intermediaries (who may know the accountor better or have a very positive relationship with him/her), in order to indirectly exert influence on the accountor (Frink \& Klimoski 1998; Yukl 1998). Furthermore, one could argue that beyond the transmission of the original instruction/request, at which point some mutual influencing will, by definition, occur, there may not be any need or opportunity for any further direct contact. The model would gain in veracity if the possibility of such indirect influencing were reflected in the model. [oversimplification in graphical model]

In short, Katz \& Kahn's (1978) model was highly influential in putting mutual influencing behavior on the agenda. However, it leaves off some key factors that are, in fact, mentioned in the text, thus being incomplete in reflecting the theory. Also, some of the linkages shown are problematic, others are missing altogether, and parts are oversimplified. 


\subsection{Frink \& Klimoski’s (1998) Role Episode Model}

The Frink \& Klimoski (1998) Role Episode Model borrows heavily from role set theory and Katz \& Kahn's model. Essentially the Role Episode Model depicts the interaction of Role Senders and a Focal Person, whereby the Role Sender's behavior is influenced by "expectations", and the Focal Person's "reactions" are subject to certain "perceptions" and "expectations". This interactive process, in turn, is influenced by the Focal Person's "attributes", by "interpersonal factors", and by a medley of other factors. The Role Episode Model contravenes several of the guidelines for effective graphic modelling. These are specified in the detailed critique of the model below.

Figure 2: Frink \& Klimoski's (1998) Role Episode Model

Source: Frink \& Klimoski (1998: p.23)

(Dotted circles, dotted arrows and question marks by authors of this paper)

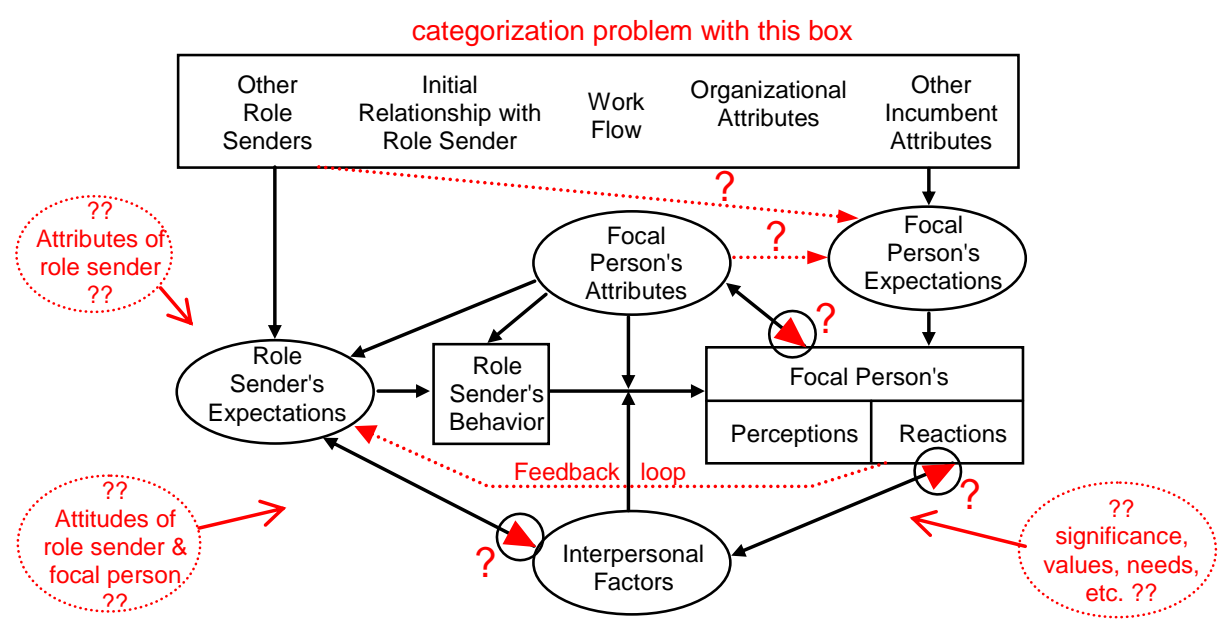

The following references are from Frink \& Klimoski (1998, p.24-25). Where some of the criticisms of the Frink \& Klimoski model also applied to its precursor, these criticisms are repeated below in abbreviated form only.

- The text states that "identified in the figure . . are personal traits or attributes of both the sender and target." However, the sender's attributes are not shown on the model (see Katz \& Kahn critique). [missing entity]

- $\quad$ In addition to the attributes of both Role Sender and Focal Person, a number of other factors mentioned in the text should be included for both (see Katz \& Kahn critique), since these "will have a strong impact" on how an accountee is likely to behave in any given accountability exchange (Frink \& Klimoski 1998, p.25). [missing entities and oversimplification]

- $\quad$ The model suggests that the Focal Person's expectations are not influenced by the Focal Person's attributes or traits. Contrary to this, by definition, a generally optimistic person would hold somewhat different expectations from a generally pessimistic person (Seligman 1990). [missing linkage]

- $\quad$ Another important dimension, attitudes, is missing completely from the model (see Katz \& Kahn critique). [missing entity]

- $\quad$ The interpersonal relationship is shown as impacting on the Role Sender only (see Katz \& Kahn critique). [flawed linkage]

- $\quad$ The model shows "Interpersonal Factors" impacting directly on the Role Sender's expectations (see Katz \& Kahn critique). [missing linkage] 
- The link "focal person's attributes" and "focal person" (arrow 6) is shown the wrong way round (see Katz \& Kahn critique). [flawed linkage]

- $\quad$ The model makes no provision for the possibility of indirect influencing occurring (see Katz \& Kahn critique). [oversimplification]

- $\quad$ The model proposes that "Other Role Senders" have an impact on the Role Sender, but not on the Focal Person, which is at odds with multiple constituency theory (Katz \& Kahn 1978; Ferris, Mitchell, Canavan, Frink \& Hopper 1995; Frink \& Klimoski 1998). The model's authors (p.7) themselves state that, "in a customer-focused organization, an employee has at least two salient sources of accountability: the customer and the organization". [inconsistent with established theory and authors' text]

- $\quad$ The feedback loop from the Focal Person to the Role Sender, a key component of the original Katz \& Kahn (1978) model, has been left off altogether. [missing linkage]

- $\quad$ The flow is not fully explained in the text, and is difficult to follow. Note that Katz \& Kahn's (1978) original model, which adopts the Gestalt principle of continuity, is much easier to interpret. In terms of Ware's (2000) criteria, the Katz \& Kahn model requires less pre-attentive processing. Simply extracting the linkages from the two models clarifies this point (see Figure 4 and Figure 5). Note also the different graphic conventions for the arrows. Katz \& Kahn (1978) use solid arrows for process lines and dotted arrows for influencing lines, to assist understanding. Frink \& Klimoski use solid lines throughout their model. [graphic confusion]

Figure 4: Role Episode Model (excerpt) Source: Katz \& Kahn (1978)

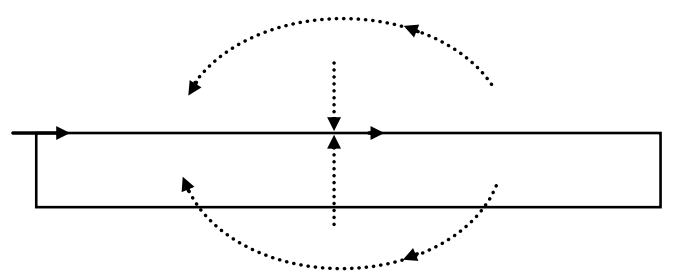

Figure 5: Role Episode Model (excerpt) Source: Frink \& Klimoski (1998)

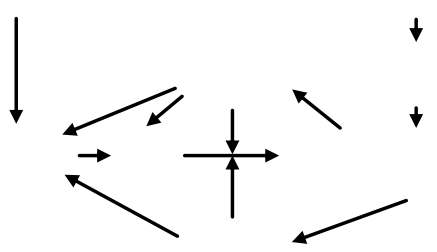

The box at the top of the model (Figure 3) refers to a disparate collection of items including accountors, a relationship, a process, organizational attributes, and attributes of accountees. The reason for grouping these elements together appears neither justified, nor is it explained in the text. In terms of category theory and good science (Rosch 1978; Feigl 1988; Howard 1999; Klein 1999), the elements are neither organized into hierarchies of relative complexity or into sub-units of a basic unit; nor do the members of this group share common salient attributes, or category resemblance; nor are they part of a structure or taxonomy. In short, they lack functional comparability, and are arbitrarily limited by category. The term "Other Incumbent" in this box is not explained in the text. Since "Other Role Senders" are specifically identified, presumably "Other Incumbents" refers to others who are to be held accountable. [indiscriminate mixing of entities; use of undefined entity]

- $\quad$ On Katz \& Kahn's (1978) model, the entities are shown in rectangular boxes, various role parameters relating to these entities are shown as subdivisions of the lower half of the rectangles, and influences are shown as ovals. In other words, content categorization is reinforced by graphic syntax. Frink \& Klimoski have rendered this graphic syntax meaningless by taking "Role Sender's Expectations" out of the rectangle, and putting it in an oval. Some may regard this as a trivial point, but it is analogous to employing text in which an adjective is mixed in among a list of verbs, for that is the textual equivalent of randomly changing graphic syntax. [meaningless graphic syntax] 
Using the typology proposed by the ORACle model, the two models compared above include entities, actions, psycho-social factors, organizational factors, influence relationships and process lines. Reducing the various model components to abstract glyphs that merely represent category types, clearly demonstrates the incoherent architecture of the Frink \& Klimoski model on the left, versus the tight architecture of the Katz \& Kahn model on the right.

Figure 6: Comparison Of Categorization Logic Of Two Models
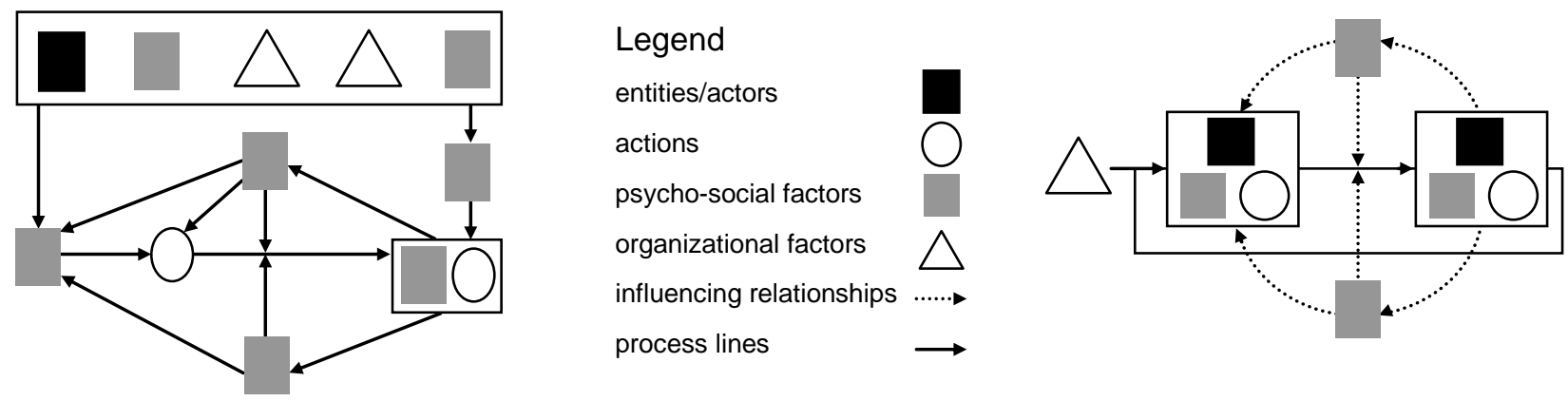

Frink \& Klimoski's (1998) Role Episode Model therefore is a rather poorer interpretation of Katz \& Kahn's (1978) original model, particularly since it leaves out one of the key components of that model for no conceivable gain, and makes graphic changes that subvert Katz \& Kahn's graphic syntax, thus making the model less intelligible. The model also does not recognize the role that intermediaries may play as part of a role episode. Frink \& Klimoski (1998, p.26) acknowledge that their role episode model "is admittedly a simplification of the forces operating on individuals as they go about the building and managing of relationships in work settings. One aspect of this simplification is that the rate of change in expectations or relationships can only be hinted. A second simplification is that role theory envisions that multiple relationships are being built or managed at any one time. A third is implied in the distinction between role taking and role making." While some simplification may be justified, or, indeed, necessary, the problems that we have alluded to above, appear to have their source in lack of graphic rigor.

\section{Conclusions}

We have argued that management scholars and practitioners are not well versed in using graphics as a form of communication, despite its advantages in depicting and explaining complex organizational processes such as accountability. We have presented some guidelines for designing effective graphics, and then used them to evaluate the graphical communication of two popular models relating to the mutual influence part of accountability. The purpose of comparing these two graphical models has not been to embarrass the authors, but to show how, by overlooking or disregarding the syntax and other principles for designing effective graphics, confusion and poor communication result. The intention is to assist readers in designing and interpreting graphical models, and to highlight the importance of graphic literacy in management.

Notwithstanding their various flaws, the Frink \& Klimoski (1998) Role Episode Model, and its Katz \& Kahn precursor, provide useful vehicles for mapping out the complexity of the typical accountability interaction between an accountor and an accountee. The models can be developed further to overcome the various deficiencies identified above, and at the same time significantly expand their scope to more accurately reflect the complexity of mutual influencing behavior. Such a model has been developed by the authors, but is the subject of another paper. 


\section{References}

1. $\quad$ Avery, G.C. \& Baker, E. 1990. Psychology at Work. $2^{\text {nd }}$ edn. Sydney: Prentice Hall.

2. Barwise, J. \& Etchemendy, J. 1995. "Heterogeneous logic", in J. Glasgow, N.H. Narayan \& B. Chandrasekaran (eds.). Diagrammatic Reasoning: Cognitive and Computational Perspective. Cambridge, Mass: AAAI Press.

3. Beattie, V. \& Jones, M.J. 1992. "The use and abuse of graphs in annual reports: Theoretical framework and empirical study", Accounting and Business Research, 22(88), 291-303.

4. Bergsteiner, H. 2003. "Modelling accountability complexity: A meta-theory", Unpublished PhD thesis. Sydney: Macquarie University.

5. Bergsteiner, H. \& Avery, G.C. 1999. "Graphical models in management: Some guidelines", Proceedings of the $5^{\text {th }}$ International Meeting of the Decision Sciences Institute, Athens, 1, 177-180.

6. Branch, G. 1999. "Spiraling towards the 'perfect' product", Machine Design, 71(17), S14.

7. Britt, D.W. 1997. A Conceptual Introduction to Modeling: Qualitative and Quantitative Perspectives. Mahwah, NJ: Erlbaum.

8. Feigl, H. 1988. "The scientific outlook: Naturalism and humanism”, in E.D. Klemke, R. Hollinger \& A.D. Kline (eds.). Introductory Readings in the Philosophy of Science. Buffalo, NY: Prometheus Books.

9. Ferris, G.R., Mitchell, T.R., Canavan, P.J., Frink, D.D. \& Hopper, H. 1995. "Accountability in human resources systems", in G.R. Ferris, S.D. Rosen \& D.T. Basman (eds.). Handbook of Human Resource Management. Oxford: Blackwell Business.

10. Freedman, D.A. 1985. "Statistics and the scientific method", in W. Mason \& S.E. Feinberg (eds.). Cohort Analysis in Social Research: Beyond the Identification Problem. New York, NY: Springer.

11. Frink, D.D. \& Klimoski, R.J. 1998. "Toward a theory of accountability in organizations and human resources management", Research in Personnel and Human Resources Management, 16, 1-51.

12. $\quad$ Fry, E. 1981. "Graphical literacy", Journal of Reading, 24(5), 383-390.

13. Gigerenzer, G. \& Selten, R. 2001. "Rethinking rationality", in G. Gigerenzer \& R. Selten (eds.). Bounded Rationality: The Adaptive Toolbox. Cambridge, MA: MIT Press.

14. Glaser, B.G. \& Strauss, A.L. 1967. The Discovery of Grounded Theory. Chicago, IL: Aldine Publishing Company.

15. Hempel, C.G. 1988. "Studies in the logic of explanation", in E.D. Klemke, R. Hollinger \& A.D. Kline (eds.). Introductory Readings in the Philosophy of Science. Buffalo, NY: Prometheus Books.

16. Hesse, M.B. 1970. Models and Analogies in Science. Indiana: University of Notre Dame Press.

17. Howard, R.W. 1999. "Reconceptualizing learning", Review of General Psychology, 3(4), 251-263.

18. Kahn, R., Wolf, D.M., Quinn, R.P., Snoek, J.D. \& Rosenthal, R.A. 1964. Organizational Stress: Studies in Role Conflict and Ambiguity. New York, NY: Wiley.

19. Katz, D. \& Kahn, R.L. 1978. The Social Psychology of Organization. $2^{\text {nd }}$ edn. New York, NY: Wiley.

20. Keidel, R.W. 1995. Seeing Organizational Patterns: A New Theory and Language of Organizational Design. San Francisco, CA: Berrett-Koehler.

21. Klein, H. 1999. "Does modeling the real world in object oriented systems result in well-structured systems?", Proceedings of $5^{\text {th }}$ International Conference, Decision Sciences Institute, II; 1065-1069. Athens Greece: New Technologies Publications.

22. Kleinman, G. \& Palmon, D. 2000. "A negotiation-oriented model of auditor-client relationships", Group Decision \& Negotiation, 9(1), 17-45.

23. Knight, M. 1999a. "Writing and other communication standards in undergraduate business education: A study of current program requirements, practices, and trends", Business Communication Quarterly, 62(1), $10-28$.

24. Knight, M. 1999b. "Management communication US MBA programs: The state of the art", Business Communication Quarterly, 62(4), 9-32

25. Laughlin, R.C. 1995. "Empirical research in accounting: alternative approaches and a case for "middlerange thinking", Accounting, Auditing \& Accountability Journal, 8(1), 63-87.

26. Li, J. \& Zhang, M. 1997. "A new modeling approach to business processes", Proceedings of the Fourth International Meeting of the Decision Sciences Institute, Sydney, July, 395-397. 
27. Markham, S.E. 1998. "The scientific visualization of organizations: A rationale for a new approach to organizational modelling”, Decision Sciences, 29(1), 1-23.

28. Mintzberg, H. \& Van der Heyden, L. 1999. "Organigraphs: Drawing how companies really work", Harvard Business Review, 77(5), 87-94.

29. Murranka, P.A. \& Lynch, D. 1999. "Developing a competency-based Fundamentals of Management Communication course", Business Communication Quarterly, 62(3), 9-23.

30. Nadler, D. A., Gerstein, M. S., Shaw, R. B. \& Associates, 1992. Organizational Architecture: Designs for Changing Organizations. San Francisco, CA: Jossey-Bass.

31. Nersessian, N.J. 1995. "Capturing the dynamics of conceptual change in science", in J. Glasgow, N.H. Narayan \& B. Chandrasekaran (eds.). Diagrammatic Reasoning: Cognitive and Computational Perspective, Cambridge, Mass: AAAI Press.

32. Paivio, A. 1978. "Dual coding: Theoretical issues and empirical evidence", in J.M. Scandura \& C.J. Brainerds (eds.). Structural Process Models of Complex Human Behavior. Alpen aan den Rijn, Netherlands: Sijthoff \& Noordhoff.

33. Piggot, M. 2002. "Looking beyond traditional models", Marketing Research, 14(3), 8-11.

34. Pitt, J.C. 1981. Pictures, Images, and Conceptual Change. Dordrecht, Holland: Reidel Publishing Company.

35. Pylyshyn, Z.W. 1980. "Computation and cognition: Issues in the foundations of cognitive science", Behavioral and Brain Sciences, 3, 11-133.

36. Rosch, E. 1978. "Principles of categorization", in E. Rosch \& B.B. Lloyd (eds.). Cognition \& Categorization. Mahwah, NJ: Erlbaum.

37. Seligman, M. 1990. Learned Optimism. New York, NY: Pocket Books.

38. Soulliere, D., Britt, D.W. \& Maines, D.R. 2001. "Conceptual modeling as a toolbox for grounded theorists", Sociological Quarterly, 42(2), 253-269.

39. Staats, A.W. 1999. "Unifying psychology requires new infrastructure: Theory, method, and a research agenda", Review of General Psychology, 3(1), 3-13.

40. Tractinsky, N. \& Meyer, J. 1999. "Chartjunk or goldgraph? Effects of presentation objectives and content desirability on information presentation", MIS Quarterly, 23(3), 397-420.

41. Trumbo, J. 1997. "The process of critique in visual communication", Journalism and Mass Communication Educator, Summer, 15-23.

42. Tufte, E.R. 1983. The Visual Display of Quantitative Information. Cheshire, CT: Graphics Press.

43. Tufte, E.R. 1990. Envisioning Information. Cheshire, CT: Graphics Press.

44. Tufte, E.R. 1997. Visual Explanations. Cheshire, CT: Graphics Press.

45. Van Dam, L. 1992. "A picture is worth 1,000 numbers", Technology Review, 95(4), 34.

46. Van Sell, M., Brief, A.P. \& Schuler, R.S. 1981. "Role conflict and role ambiguity: Integration of the literature and directions for future research", Human Relations, 34(1), 43-71.

47. Vessey, I. 1991. "Cognitive fit: A theory-based analysis of the graphs versus tables literature", Decision Sciences, 22, 219-240.

48. Wainer, H. \& Velleman, P.F. 2001. "Statistical graphics: Mapping the pathways of science", Annual Review of Psychology, 52, 305-335.

49. Walker, J.A. \& Chaplin, S. 1997. Visual Culture. Manchester: Manchester University Press.

50. Wardrope, W.J. \& Bayless, M.L. 1999. "Content of the business communication course: An analysis of coverage", Business Communication Quarterly, 62(4), 33-40.

51. Ware, C. 2000. Information Visualization: Perception for Design. San Francisco, CA: Morgan Kaufmann.

52. Yukl, G. 1998. Leadership in Organizations. London: Prentice-Hall International. 